\title{
ATTRIBUTES OF SELF-DEVELOPING SOCIO-ECONOMIC SYSTEMS
}

Place of the concept "self-developing socioeconomic systems" within the context of similar economic categories is considered in the paper. As a result of the analysis of the existing approaches, author's criteria of singling-out self-developing regions including Gross Regional Product and financial balance of a territory are defined.

In the context of the policy of system modernization of socio-economic development of the country and single territories adopted by the government, an interest to the problems related

\footnotetext{
${ }^{1}$ The paper is completed with financial support from the project 09-П-1003 "Regularities of generation and functioning of selfdeveloping economic systems based on advanced organizational and administrative technologies"
}

to sustainable development of territorial systems has been growing in the last few years. Therewith, a new concept of sustainable socio-economic development of territories is concerned with search for internal reserves and mechanisms that secure economic growth and well-being of the population. Thereupon, treatment of the mentioned problems in terms of the category «self-development» could, in our opinion, become fundamental in specification of mechanisms and methods of stimulation of aimed at economic upgrading of certain territories.

Scientists engaged in the study of physical and biological systems have long come to the fore in research of self-development processes. However, subjects of research into self-development have considerably extended for the last few years, and 
involved new branches of knowledge to the research into the given phenomenon. The concepts of selfdevelopment, along with self-organization and selfregulation, were introduced into economics.

\section{Self-development as a concept: attributes}

What are self-developing systems? What is the difference between self-organized and self-regulated systems?

All the mentioned concepts are close in terms of the meaning. Thuerefore, this often raises questions related to their definition. In particular: what is primary - self-organization or selfregulation? Some authors follow the logic of system development, such as: "...In the process of selfregulation and adaptation to changing conditions of the environment change of the system organization, i.e. self-organization, occurs" [16, p. 50]. It can be deduced from the citation that it is exactly selfregulation that leads to self-organization, rather than the reverse. In addition, D. K. Chistilin, when considering the process of social system development, uses the concept of «self-administration», which is to a certain extent identified with self-regulation and interpreted as change of organizations that adapt the system to changing environmental conditions.

Other authors do not establish a cause and effect relationship between the concepts considered, and they talk about the forms of self-regulation [6]. The first form of self-regulation is self-regulation on the feedback basis; such self-regulation is accomplished as self-adjustment with system parameters changing subject to external environment change. The second form of self-regulation is self-organization, with the effects attended by changes in the system structure.

In some works researchers unite the selforganization principle in terms of integrity, selfsufficiency, self-regulation, self-preservation, selfreproduction, self-optimization and, finally, selfdevelopment [2]; they assert that analysis of the above-mentioned self-organization principles is indicative of their orderliness and complementarity.

It is rather difficult to agree with the given statement, as the mentioned principles are

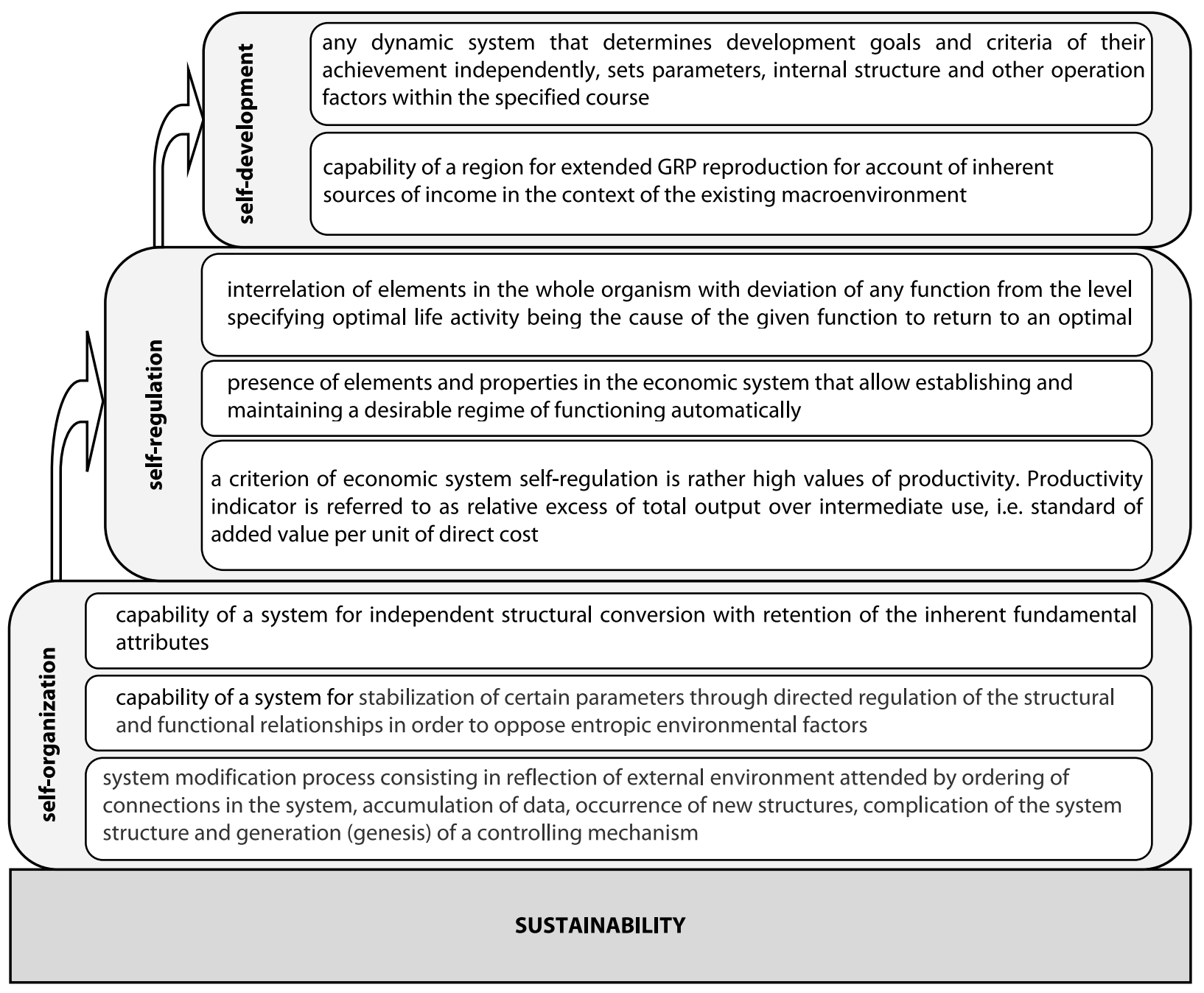

Fig. Interrelation of concepts related to system development 
complementary; therefore, it is possible to arrange them in a certain sequence, but it is a matter of controversy if they can be united in terms of selforganization, so far as there are definitions of selforganization for both any system, and particularly an economic one, in which the given process is identified as spontaneous [15]. It is a problem to apply spontaneity to self-regulation or selfreproduction, and the more so, to self-development.

In the definitions of self-organization and selfregulation given on the figure, there is one more essential distinction: self-organization is a system change process or system capability; while selfregulation assumes elements, properties, a certain level of rates, etc. in a system.

Thus, scientists of different fields of knowledge do not have clear definition regarding which of the "self-" concepts is primary, and which one is the following stage of system evolution. With a view of our research, let us make an effort to rank the terms under investigation.

A sequence "self-organization, self-regulation, self-development" is, in our opinion, the most logical. The following reasoning forms the basis of the mentioned chain. Self-organization of a system is putting internal elements in a certain condition in order to "oppose entropic factors of the environment" or "reflection" of the environment". As a result of the given process both regulation, and complication of the structure occur, and qualitative characteristics of the system improve.

Complication of the system structure is a consequence of enhancement of the role of selfregulation in the economy (which is proved by explanation in the Modern Economic Dictionary [1]). As an example, transition of the Russian economy from the command system to the market economy can be mentioned; as a result of such transition, amount of economic entities that regulate their activity independently and cooperate with contractors and government bodies, i.e. external environment, grows. Another attribute of self-regulation is ability to secure sustainability of the processes [11]. It was during the post-soviet time that research into a sustainability condition was of particular interest. Since that time many techniques and methodological approaches to assessment of sustainability (financial one, in particular) of enterprises, commercial banks, insurance organizations, bank and financial systems, etc., have appeared.

In 1996 the problem of sustainability was raised at the national level; in April an RF Presidential Edict "On the concept of transition of the Russian
Federation to sustainable development" was issued. We shall revert to the matter of sustainability later.

The following stage of socio-economic system evolution is self-development. The most common definition of a self-developing system is "a complex of elements (systems, subsystems, parts) organized into a structure capable of steadily developing with no (or minimum) external sources of development involved" [4, 5, 12, 14].

When estimating self-development potential of systems, particularly socio-economic ones, the fact that the given concept is borrowed from mathematics and mechanics is to be taken into consideration. Representatives of mechanics refer to self-developing systems as any dynamic system, which defines independently development goals and criteria of achievement of the given goals, sets parameters, internal structure and other relevant characteristics.

Traditionally, self-development processes are most harmonious in the ambient biosphere, and they occur on the basis of heredity, natural selection and variability mechanisms. In terms of heredity and natural selection there is unanimity of views regarding specifics of functioning of social and economic systems in the literature dedicated to self-developing systems; however, there is still no such unanimity regarding variability. The given fact is often due to uncontrollable variability being extraneous both to tectology by A. A. Bogdanov, and all mechanical and mathematical systems, so far as it makes essentially unpredictable the result of any changes and bifurcational (revolutionary) reconstruction, under the influence of which the memory of the system virtually disappears, and its future functioning is determined by spontaneous scholasticism and lack of system-preserving pur-poses [7, 9].

Along with the concepts considered, another one, which is very close to them in terms of the content - an adaptation process, is to be mentioned. The term «adaptation» is used in economics, biology, mathematics, psychology and many other branches of knowledge. Definition of the given process has its specifics reflected in subjects of research within the framework of each mentioned discipline, but generally adaptation is referred to as adjustment to the outside world. That is inherent in the name: adaptation is adaptatio in Latin, i.e. adjustment. Adaptation in economics is understood as adjustment of an economic system and its components, workers, to changing conditions of external environment, production, labor, exchange, life [1, p. 26].

E. D. Sorokin in his work "Self-regulation in Economy" unites all the concepts considered 
above very well [10]. According to E. D. Sorokin, a system can be sustainable in case it is capable of self-regulation and self-development, i.e. capable of adapting to changes in functioning conditions independently. Such systems have been named "adaptive systems", and they have a number of inherent properties, the following being the most significant:

- self-adjustment property, specified by positive changes of system functioning parameters for account of internal self-organization;

- self-organization property assumes capability of a system to transform its structure independently with preservation of major inherent qualitative characteristics;

- self-training property, i.e. capability of independent selection of conditions for the system to meet the criteria of functioning quality.

R. Bellman and R. Kalaba proceed further, defining generally the concepts of adaptation, selforganization and self-regulation [17, p. 7]. The definition is as follows: "gradual change of average properties in stochastic environment of dynamic system functioning". Here two facts are to be emphasized. First, the order of terms established by the authors. Despite the fact that the order was established for the systems studied by natural sciences, it conforms with humanist systems as well. Second, the phrase in the definition "change of average properties". It is exactly average rates that will further form a basis for development of the technique related to assessment of regional self-development.

Reasoning from above-said, self-development is referred to as an ability of a region to secure extended reproduction of gross regional product at the expense of proper sources of income in the existing macroenvironment [13, p. 32].

After scientific definitions of self-organization, self-regulation and self-development have been given adequate consideration, we shall instantiate them in a way clear to laymen.

By convention, the specified stages of economic development can be extended to age stages of human life. During the infancy period a child makes attempts to organize work of the motor apparatus and cerebration, he coordinates his internal structure, orders his demonstrating efforts, starts to creep, walk, hold a spoon, speak. Thus, the elements of the system improve in quality due to internal self-organization, growth and opposition to external environment. It is possible to talk about self-organization at this stage.

Later on a child attends a nursery school, then secondary school, institute, he meets a community of children and adults, obtains knowledge and other information. At this point it is a problem to speak of opposition (constant) to the ambient world, as a person should interact with it for the purpose of full-fledged development. However, the obtained information should be estimated and perceived, a part of it will be eliminated. The environment is selected independently, and conflicts and controversy arising in the course of communication are settled. I.e. a child (teenager) reacts independently to external influence that prevents him from progress, selfaffirmation or, on the contrary, contributes to it. At this point it is possible to speak of a certain self-regulation of a person, when he chooses ways to overcoming environmental influences and finds optimal conditions for life support.

The highest stage is self-development. The education period is finished, adult life comes, necessity to demonstrate knowledge, skills and initiative arises, which determines further goals. A person establishes parameters of development independently, estimates weak points and progresses cherished goals, i. e. he self-develops.

Considering the above-mentioned example, it can be noted that a person does not always choose a good purpose in the process of self-development, and achievement of such a «negative» goal cannot be regarded as self-development. The same can be applied to self-development in socio-economic systems as well; therefore, it is advisable that determination of a goal was treated with caution when determining a vector of self-development.

There is no doubt that a lot can be said about the purposes of territorial development, which may vary from purely economic to social ones. It is very popular today to focus any concept under definition on a level and quality of people's life. In our opinion, such an approach is not always justified, so far as the concept of socio-economic systems already comprises a social component that reflects and estimates well-being of the population on a territory. As a result, any processes concerned with development of a territory as a whole and its components are aimed at improvement of living conditions. At the same time, in the context of self-development we can consider processes or conditions (in definition of which a standard of wellbeing is not determinative), under which the leading role is assigned to an economic component. Along with that, condition of the social sphere will be the result of economic prosperity of the region, i.e. the result of self-development (but not the goal).

Concluding the theoretical block of the concepts used to describe socio-economic system 
sustainability, it would be desirable to focus on an issue related to correlation of concepts of "sustainability of development" and "sustainability of self-development". When studying concepts beginning with «self-», obvious or hypothetical presence of external environment is always noted. At the same time, sustainability is generally defined as an ability to resist environment influences with the internal structure being preserved. As a result, it is difficult to determine what is primary - sustainability of a territory or ability to selfregulation and self-development. According to E. Sorokin, sustainability of a system is determined by ability for self-regulation and self-development. A similar point of view is stated by V.B. Gusev: “...A concept of economic system sustainability assumes presence of mechanisms of self-regulation capable to parry crisis phenomena..." [3].

In our opinion, the authors are right in part, since they consider sustainability condition in broad sense; as a result, there is the following order: selfdevelopment and self-regulation predetermines sustainability. It is exactly potentially sustainable territories that are able to maintain a certain structure and resist environment influences, i.e. self-organize, regulate their functioning independently and selfdevelop. However, the listed abilities, in turn, become prerequisites to development of a higher level - sustainable development of a territory.

\section{Identification criteria of self-developing regions}

In the definition of self-developing regions given above, there are two fundamental criteria of attribution of territories to the given category: extended reproduction of the GRP and provision with proper sources of income. On this basis, we shall consider the mentioned criteria in terms of practical application in more detail.

At present, a "GRP (gross added value of a region)" rate is calculated for the regions of Russia; the given rate specifies the result of production of goods and services according to the general methodological approaches of the system of national economic accounting.

With a view to define self-developing regions, a question referred to basic principles of comparison of territories is to be answered. First of all, let us define the notion of "extended reproduction of the GRP”.

Reproduction is referred to as continuous motion and renewal of life production process in any system - biological (for instance, an individual, population, biogeocenosis, ecosystem) or social (for instance, an individual, family, community, country, capital).
The process includes reproduction of elements of the system, relations between them and interaction with external environment. Production is renewed in the economy on an invariable scale under simple reproduction, on an extended scale - under increasing reproduction and on a decreasing scale under narrowed reproduction. Therewith, extended reproduction can be accomplished extensively (for account of involvement of more resources in the economic turnover) and intensively (for account of more efficient use of available resources) [9].

Provided the given definition taken as a basis, any GRP growth is ground for self-development according to the given criterion at a set interval. At the same time, according to the statistics regarding GRP growth in recent years, it is evident that virtually all the regions (with rare exception) had positive growth rates. The given fact can be caused by various factors, but, in our opinion, the major among them was the macroeconomic situation in the country. On the other hand, GRP of territories is being synchronously reduced to some extent during business slowdown, and in this case we can talk about the lack or small amount of selfdeveloping territories in our country. Therewith, self-development is theoretically a relative and averaged value in relation to higher-order systems, and that requires specification of the calculation methodology related to regional reproduction.

On this basis, we suggest another approach to definition of self-development in terms of the GRP criterion. It consists in definition of self-development based not on regular extended reproduction of a region (i.e. GRP positive growth rates), but on a higher-order system - the economy of the Russian Federation.

In this case, self-development in terms of the GRP extended reproduction criterion is priority development of regional economy in comparison to annual average values for the Russian Federation in general.

Thus, self-developing territories are the so-called growing-points that secure capital contribution to priority development of the national economy. On the other hand, during macroeconomic slowdown or crisis periods the given approach allows defining selfdevelopment of territories under general decline or growth retardation through comparative description of sustainability of a territory to external influences: «strong» regions will show less slowdown, and «weak» regions' growth rate decline will correlate more with the national rates.

An important point of the suggested methodological approach to definition of self-development 
in terms of the GRP criterion is account for dynamic characteristics of territorial development. It is no secret that development of territories is of discrete, erratic nature, and region's GRP may show different dynamics during different periods. It is particularly specific of fast-developing regions, as well as territories with low initial potential. In this case, owing to exploitation of large capacities in a territory, GRP may have spasmodic dynamics that is not quite indicative of the actual processes. Therefore, research into GRP is suggested that it be conducted on the basis of average rates for as large time interval as possible (for instance, for the last 10 years), that covers different periods of economic development of our country.

After the detailed consideration of the first criterion of territorial self-development, let us proceed to another one - provision with proper sources of income.

In our opinion, substantiation of specific rates securing appropriate description of the given criterion is rather difficult from the practical point of view and data content.

The point is that it is necessary first of all to decide on what proper sources of income of territories are. In broad sense, sources of income of any territory are an aggregate of monetary funds received from various sources by various institutional units that are residents of the given territory. Thus, on the basis of the definition, we should allow for sources of income of all business entities of the territory including funds of enterprises, population, budgets of all levels, financial companies etc.

However, it is virtually impossible to estimate sources of income in the current accounting system of financial flows at a local level. At a territorial level flow of funds are virtually not reflected at the level of enterprises and population; financial organizations, as a rule, render account to higher subdivisions, etc. All that restricts the choice of a methodological approach to definition of rates determining the second self-development criterion.

On the other hand, the methodology of national economic accounting (NEA) makes it possible to determine financial balance of territories through balancing item rates that reflect self-sufficiency of the territory in a varying degree. For instance, based on a capital transactions account it is possible to consider self-development of a territory through a net lending rate (net borrowing), and relation of economy of the territory to external infusion - on the basis of external primary income and current transfers account, in which the rate "goods and services external transactions balance" is balancing.
A scheme of provision with proper sources of income within the NEA, which is correct in theory, faces in practice a number of methodological and methodical problems that are insurmountable at present.

According to the aforesaid, definition of more practicable and reliable system of rates is required, that allows describing financial self-sufficiency of regions in the context of the data available. Application of budget capacity rates in one form or another became the most widespread criterion of financial self-sufficiency of regions in the scientific literature in recent years.

Indeed, with lack of exhaustive information regarding financial flows in a territory, consideration of the territorial budgetary balance has logical justification. The point is that budget in terms of balance and sufficiency for reproduction process security in a territory, as well as enhancement of quality of life can be considered as a portrayal of efficiency of territorial community activities. Theoretically, activity of all economic entities set up a fiscal base for pumping up regional budgets, which is implicitly indicative of self-sufficiency of the given fiscal base. In case proper sources of income are sufficient for pumping up a territorial budget, then efficiency can be stated; in an opposite case the budget is pumped up for account of external sources, self-development cannot be stated.

Based on the given points of view, there is a widespread approach to assessment of selfsufficiency or provision of budgets with proper resources in the scientific literature. The given approach is based on correlation of proper sources of income of consolidated budgets of the Russian Federation and expenditure, including revenues from higher budgets. The techniques vary in details (various comparison bases, evaluation procedures, etc.); however, in our opinion, the given approach has a number of distinctions in kind with the essence of self-development embedded in the definition.

First of all, sources of income of territories are to be in the focus when conducting research into proper income of territories. It is a well-known fact that, according to the Budget Code, regional taxes that completely enter the budgets of the RF Constituent Entities include: corporate property tax, tax on gambling industry, transport tax. In addition, tax revenues derived from a number of federal taxes and dues are subject to enter the budgets of the RF Constituent Entities. The given taxes include: corporate profits tax, personal income tax, excise taxes, etc. At the same time, the most «profitable» taxes and dues remain under the jurisdiction of the 
federal budget, such as: the value added tax, mineral replacement tax (hydrocarbon), customs charges and export duties, etc. in the issue, the existing system of distribution of tax revenues has resulted in the fact that the share of the so-called proper income of budgets of RF Constituent Entities is being steadily reduced in terms of both total income of the state budget, and the distribution structure of the budgetary system, i.e. transfers taken into account. Therefore, skewness in the system of distribution of income sources does not allow estimating selfdevelopment potential of a territory objectively. At the same time, if budget capacity rate depended directly on the results of territorial development efficiency (for instance, by transferring a part of the VAT in the territorial budgets), then the considered approach would be more objective.

Thus, determination of budget supply in the Russian Federation more resembles a roulette game under the present conditions: the territories with the budgetary system features allowing to secure fiscal well-being will have positive results; and the territories transferring the most part of taxes to the federal budget will have an adverse effect.

Another particularity of the RF budgetary system development that does not allow estimating proper income base of RF Constituent Entities objectively is the federal budget revenue structure aimed at increase of payments from export-import transactions. It is no secret that increase in revenues of the federal budget in the last few years was secured not for account of tax payment proper, but owing to the customs duties on principal exports, and, accordingly, the duties on imports. Thus, in fact, withdrawal of a part of the added value from the regional to the federal level by way of the export duties mechanism occurred. Under such conditions the federal budget could afford reverse subsidy of regional budgets; i.e., territories with sufficient tax base to pump up the budget became subsidized due to withdrawal of a part of the added value at the federal level.

According to the reasoning given above, consideration of self-development in terms of the criterion of sufficiency of proper means on the basis of comparison of sources of consolidated budget supply of a territory is, in our opinion, not correct.

Another approach to definition of self-sufficiency of regional budgets is comparison of tax payment entering all the levels of the budgetary system and expenditure of a given territory derived from the consolidated budget. In our opinion, the given approach is more objective when considering selfdevelopment of a territory, so far as it demonstrates the way budget expenditure is secured with a proper tax base.

At the same time, the given approach has drawbacks as well. There are some of them:

- Skewness of the tax and budgetary system of the Russian Federation mentioned above is leveled incompletely within the given calculation technique. It is particularly true for export-import transactions.

- Information referred to self-sufficiency of a region is distorted due to the fact that non-tax revenues are included in the record of expenditure of consolidated budget of a territory. However, according to the Ministry of Finance of the Russian Federation, non-tax revenues are negligible (1-5\%) in the budgets of RF Constituent Entities, which allows assuming admissibility of the given approach.

- Excess of tax payment over expenditure of a territory is not self-development proper, since each RF Constituent Entity should contribute to execution of state functions in the form of transfer of a part of the revenues to a higher budget. At the same time, in the context of the existing budgetary system it is a certain convention, and therefore, the given point can be omitted from the practical calculation at the given stage of research.

What regions of the Russian Federation can be attributed to self-developing ones? What are specifics of their development and differentiation? We shall make an attempt to answer the given questions in one of the next issues of the journal.

\section{References}

1. Riesberg, B. A., Lozovsky, L. S., Starodubtseva, E. B. (2007). Adaptation. Modern Economic Dictionary. Issue 5, revised. Moscow: Infra-M, p. 26.

2. Belyaev, M. I. (2001). Milogiya. Municipal power. Krasnoznamensk: Poligraph.

3. Gusev, V. B. (2001). Scope of crisis-free functioning of economy. Issues related to complex system security management. Materials of the IX International Conference. Moscow: RSUH, pp. 38-42.

4. Danilov, Y. A., Kadomtsev, B. B. (1983). Nonlinear waves. Self-organization. Moscow: Nauka (Science).

5. Kasty, J. (1982). Large-scale systems. Cohesion, complexity, disasters. Transl. from English. Moscow: Mir, 216 p.

6. Perepyolkin, V.A. (2002). Evolutionary economy concept as an alternative definition of the mechanism of economic development. Moscow. 48 p.

7. Bezruchko, B. P., Koronovsky, A. A., Trubetskov, D. I., Hramov, A. E.; introduction by Mironov, S., Malinetsky, G.G. (2005). Way to Synergy. Excursus in ten lectures. Moscow: KomKniga, $304 \mathrm{p}$.

8. The Russian Encyclopaedia. Derived from: http://enc. mail.ru/article/1900400878

9. Selivyorstov, V.E. (2009). Federalism and regional policy in present-day Russia. Region. Economy and Sociology, 1.

10. Sorokin, E. D. (1990). Self-regulation in Economy. Moscow: Economics, p. 159. 
11. Sudakov, K. V. (2003). Evolutionary isomorphism in establishment of sustainable societies. Sustainable development. Science and Practice, 2.

12. Suspitsyn, A. S. (2008). Research into Territorial Systems. Region. Economy and Sociology, 2.

13. Tatarkin, A. I., Tatarkin D. A. (2009). Self-developing regions: macroeconomic conditions of establishment and functioning mechanisms. Scientific expert. Issue 1-2. pp. 32-54.

14. Theory of economic order. "Freiburg School" and German neoliberalism. Transl. and ed. by V. Gutnik. Moscow: Economics, 2002.

15. Hacken, G. (2006). Information and self-organization. Macroscopic approach to complex systems. Moscow: LKI Publ. 297 p.
16. Chistilin, D. K. (2000). Problems of self-organization in transition economies. Economy of Ukraine, 3, pp. 56-62; 4, pp. 49-54.

17. Bellman, R., Kalaba, R. (1960). Dynamic programming and adaptive control processes: Mathematical foundation. IRE Trans. on Automatic Control. Vol. AC-5. pp. 5-10.

\section{UDC 332.012.2}

keywords: self-development, regions of the Russian Federation (RF regions), self-regulation, Gross Regional Product (GRP), financial balance of territory 